\title{
The Difficulty Analysis of Students Spatial Ability Based on Level Van Hiele in Problem Based Learning
}

\author{
Chairunnisa $^{1}$, Edy Surya ${ }^{2}$, Bornok Sinaga ${ }^{3}$ \\ ${ }^{1}$ Postgraduate Program in Mathematics Education Department, Universitas Negeri Medan, Indonesia \\ ${ }^{2,3}$ Universitas Negeri Medan, Indonesia \\ chairunnisa091@gmail.com
}

\begin{abstract}
This study aims to (1) determine the level of students' spatial ability at Van Hiele's level in problem-based learning. (2) to find out the location of the students' difficulties in solving spatial power problems with the Van Hiele level. This research is a qualitative descriptive study. The subjects of this study were students of class XII SMK Bima Utomo Batang Kuis. The object of this research is the spatial ability based on Van Hiele's level in Problem Based Learning. The results of this study indicate that the level of spatial ability in the low category reaches $51.4 \%$, while the medium category reaches $34.3 \%$, and the high category reaches $14.3 \%$. Subjects in the low category experienced skill difficultiesSubject S.O1 (low spatial ability), at Level 1 experienced skill difficulties (question number 1) and concept difficulty (question number 4), at Level 2 experienced skill difficulties, at Level 3 and Level 4 experienced difficulty in principle. Subject S.O2 (low spatial ability), has difficulty skills at Level 2 and has difficulty in principle at Level 3 and Level 4. Subject S.03 (moderate spatial ability), has difficulty in principle at Level 3 and Level 4. Subject S. 04 (moderate spatial ability), has difficulty skills at Level 3 and has difficulty in principle at Level 4. Subject S.05 (high spatial ability), has difficulty in principle at Level 4. Subject S.06 (high spatial ability), has difficulty principles at Level 4.Based on the results of this study, it is expected to be an inspiration for users.
\end{abstract}

Keywords spatial ability; Van Hiele; problem based learning

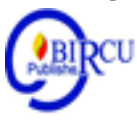

\section{Introduction}

Mathematics is broadly divided into four branches, namely Arithmetic, Algebra, Geometry, and Analysis (Bell in Abdussakir and Nur laili Achadiyah, 2009: 388). Learning geometry is one of the important things in mathematics because geometry supports many topics that are very important in problem solving. The objectives of learning geometry are to develop logical thinking skills, develop a spatial visual core of the real world, impart the knowledge needed for advanced mathematics and are also expected to teach how to read and interpret mathematical arguments. Mathematics is a universal science. Mathematics is also seen as the queen of science (Irhamna, 2020). Behind the study of geometry, the ability to study geometry is needed, especially in its application in life.

Spatial ability is a concept in spatial thinking. Linn and Petersen (National Academy of Science, 2006: 44) classify spatial abilities into three categories, namely: (1) spatial perception, (2) mental rotation, and (3) spatial visualization. Viewed from the context of mathematics, especially geometry, it turns out that spatial ability is very important to 
improve, this is based on the results of the following research. In the National Academy of Science (2006: 45) it is argued that every student should strive to develop skills and spatial sensing which are very useful in understanding relationships and properties in geometry to solve mathematical problems and problems in everyday life. One of the teacher's main tasks is teaching. To be able to teach mathematics, a teacher must be able to prepare lesson plans so mathematics lessonscan be received by students (Nasution, 2020).

If viewed from the context of everyday life, spatial abilities also need to be improved, this refers to the opinion of Barke and Engida (2001: 237) who suggest that spatial ability is a major intelligence factor that is not only important for mathematics and science, but also necessary for success in many professions. Gadner (Republika on line, 2008) who basically writes that children need spatial abilities in exploration activities, for example when children paint, color, paste, play with folding paper. A pilot also really needs a high level of spatial ability to know well where the ground or field while he is maneuvering. Thus an architect also really needs high spatial abilities to design a beautiful shape.

In the context of the curriculum, NCTM (2000: 29) has determined 5 content standards in mathematics standards, namely numbers and their operations, problem solving, geometry, measurement, and probability and data analysis. In geometry there are elements of the use of visualization, spatial reasoning and modeling. This shows that spatial ability is a curriculum requirement that must be accommodated in classroom learning. In the national curriculum in Indonesia, from elementary school to tertiary education level students are required to be able to master the material of field geometry and spatial geometry which also requires spatial abilities.

One of the education experts who also pay attention to the level of cognitive abilities is Van Hiele. The research conducted by Van Hiele gave birth to several conclusions about the stages of children's cognitive development in understanding geometry. The low learning outcomes of mathematics as stated above are not much different from the reality on the ground, including the results of learning mathematics at the junior high school level, so it needs to be studied more deeply to find the cause (Rezeki, 2020).

Van Hiele's theory states students' geometric thinking levels sequentially through 5 stages / levels. According to Slameto (2010: 13),

Van Hiele stated that there are 5 levels of children's thinking in the field of geometry, namely:

a. Level 0 (visualization). At this level students recognize geometric shapes only as visual characteristics and appearance.

b. Level 1 (analysis). At this level students have begun to recognize the properties of the observed geometric shapes

c. Level 2 (abstraction). At this level students already know and understand the properties of a geometric shape which are related to one another.

d. Level 3 (reduction). At this stage students have been able to draw conclusions deductively, namely drawing general conclusions and leading to specific matters.

e. Level 4 (rigor). At this level, students have begun to realize the importance of the accuracy of the basic principles that underlie a proof.

Learning geometry with Van Hiele's Theory is a theory about the level of thinking of students in studying geometry, where students cannot go up to a high level without passing a lower level. The development process from one stage to the next is not determined by age and biological maturity, but is more dependent on learning from teachers and the learning process that students go through. 


\section{Review of Literatures}

Basically, learning difficulties can be divided into two aspects, namely academic learning difficulties and developmental learning difficulties (Syahrir, et al. 2013). In the learning process in class in particular, academic difficulties need to be studied more deeply because it greatly affects the learning achievement of students. Learning difficulties related to academics are characterized by the failure to achieve academic achievement in accordance with what is expected. These failures or inability include failure to master reading, writing, and mathematical skills. These academic learning difficulties can be recognized by both educators and parents when the child is unable to demonstrate or achieve these academic-related abilities (Ministry of Education and Culture, 2012).

In the learning process, for example, students who have learning difficulties can be identified through certain criteria or characteristics, including what is conveyed by (Syahrir et al., 2013), this follows: (1) shows that there are low learning outcomes ; (2) the results achieved are not in accordance with the efforts made; (3) slow in completing learning activities; and (4) there is a disruption in performance. So that if students show one of these four characteristics in the learning process, it can be believed that students are experiencing difficulties in learning.

According to Fiantika (2017) "There are two types of representation, namely internal representation and external representation. The interal representation is in human mind. The external representation may include images, auditory and kinesthetic which can be used to describe, explain and communicate the structure, operation, function of the object as well as relationships "which means there are two types of representations, namely internal representations and external representations. Internal representations are also known as mental representations; this representation exists in the human mind. External representations include images, hearing and kinesthetic which are used to describe, explain, and communicate the structure, operations, functions of objects and relationships.

Van Hiele was a Dutch mathematics teacher who in 1954 wrote a dissertation on teaching geometry. In Amir and Risnawati (2016: 92) explains Van Hiele's theory of learning. Cognitive learning theory places more emphasis on the ways a person uses his thinking to learn, improve, and use the knowledge that his mind has acquired and stored effectively. The characteristics of the cognitive learning stream are as follows:

1. Concerned with what is in humans

2. Concerned with cognitive roles

3. Concerned with the current conditions

4. Concerned with the formation of cognitive structures

5. Prioritizing balance in humans

6. Prioritizing insight (understanding, understanding)

In accordance with the criteria of mathematics, learning mathematics is more likely to belong to a cognitive learning stream whose processes and results cannot be seen directly in the context of behavioral changes. So it can be concluded that basically learning is a business process that involves mental activities that occur in humans as a result of active interaction with the environment to obtain a change in the form of knowledge, understanding, behavior, skills and attitude values that are relative and lasting. .

One of the theories in the cognitive stream, namely in teaching geometry, there is a learning theory proposed by Van Hiele which describes the level of mental development of children in geometry. According to Van Hiele (in Kartono, 2010: 25-26) a person will go 
through five levels of thinking development in learning geometry. The five levels are visualization, analysis, informal education, education and rigor ".

\subsection{Level 0 (Vis ualization)}

This level is called the level of recognition, students are only new to geometric shapes such as cubes, triangles, squares and other geometric shapes, children can show triangular shapes. However, at the level of recognition, children are not familiar with the properties of geometry, so if they are asked questions about the geometric properties of children, they will not be able to answer them. The teacher must fully understand the character of the child, not to teach the properties of these geometric shapes, because the children do not understand them.

\subsection{Level 1 (Analysis)}

This level is called the description level. If at the level of recognition, children are not familiar with the properties of geometric shapes, this is not the case at the level of analysis. At this level, children can already understand the properties of geometric shapes. Children at the analysis stage are not yet able to know the relationship between a geometric shape and other geometric shapes, cannot see the relationship between some shapes and abstract definitions or cannot be understood. For example, students already know that a rectangle has two pairs of opposite sides of the same length, the length of the diagonals is the same.

\subsection{Level 2 (Informal Deduction)}

This level is often called the abstraction stage or sorting level. At this level, students' understanding of geometry has increased even more than before, who only knew geometric shapes and their properties, so at this level the child was able to know the relationship between a geometric shape and other geometric shapes Children who are at this level are able to draw conclusions deductively, but they are still at an early stage, meaning they have not developed properly. For example, students already know that a square is a rectangle, a rectangle is a line of levels.

\subsection{Level 3 (Deduction)}

At this level the child is able to understand deduction, that is, draw conclusions deductively. Deductive conclusion is drawing conclusions from specific matters. Children at this stage have understood the importance of the role of defined elements, axioms or problems and theorems. Children at this stage do not know the usefulness of a deductive system. For example: students have been able to compile evidence if the opposite sides are equal. Students have been able to develop evidence in more than one way. The reciprocal between necessary and condition is quite understood. The difference between the statement and the conversion can be understood by students.

\section{2..5 Level 4 (Rigor)}

This level is called the accuracy stage. The last stage of a child's cognitive development in understanding geometry is the stage of accuracy. At this level the child already understands the importance of the accuracy of the basic principles that underlie a proof. Children at this stage already understand that something is made into a postulate or argument. In mathematics we know the importance of a deductive system. The accuracy stage is the highest stage in understanding geometry. This level requires a complex and complicated thinking stage. Students can find differences between the two structures. 
Students understand the difference between Euclidean geometry and non-Euclidean geometry. Students understand the axioms that underlie the formation of non-Euclidean geometry.

\section{Research Methods}

This type of research used in this research is descriptive qualitative research. This research was conducted at SMK Bima Utomo Batang Kuis, Indonesia. The subjects in this study were students of class XII. To analyze the difficulty of students' Spatial ability based on Van Hiele's Level in Problem Based learning.

\section{Discussion}

The level of students' spatial abilities in three-dimensional material can be analyzed based on the results of the scoring and assessment of the overall student work. The level of students' spatial abilities is grouped into 3 (three) groups, namely: low, medium and high. From the analysis conducted that out of 35 students, there were 18 students $(51.4 \%)$ whose spatial abilities were still low, 12 students $(34.3 \%)$ were moderate, and 5 students $(14.3 \%)$ were \%) whose spatial ability is high.

More details on the percentage of students' spatial ability levels can be illustrated in Figure 1.

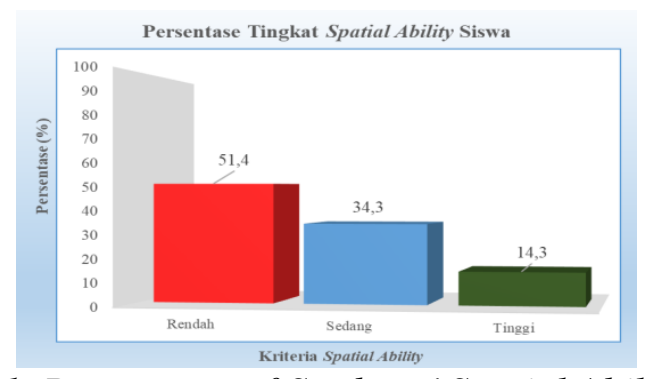

Figure 1. Percentage of Students' Spatial Ability Level

Figure 1 shows that the students' spatial ability based on the test results, the majority are still in the low category, namely 18 students (51.4\%). These results also indicate that the students' spatial ability in three-dimensional building materials based on Van Hiele's level of thinking is still low

Based on Van Hiele's geometric thinking level, S.01 is included in level 0 (visualization), because the S.01 subject can only solve questions that are classified as level 0, namely for question number 2 (spatial perception) and number 3a (mental rotation) or with In other words, the subject of S.01 is only able to recognize and identify the shape based on the form that is seen in its entirety and to describe or copy the shape of the shape.

Meanwhile, for the next Van Hiele geometry thinking level (level 1 to level 4) the subject S.01 is still having difficulty or is still unable to solve the questions correctly. The following is the work or answer process for the subject S.01 


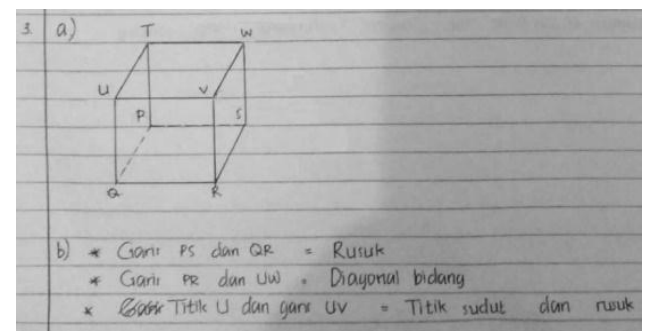

Figure 2. Results of the Subject S.01's Answers to Problem Number 3

Problem number $3 \mathrm{a}$ belongs to the level of visualization thinking (Level 0) and includes mental rotation, while $3 \mathrm{~b}$ is included in the level of informal desuction thinking (Level 2) and includes spatial relations. Figure 4.2 shows that the subject S.01 is able to solve problem number $3 \mathrm{a}$ by describing and writing the name of each corner point correctly. However, for question number $3 \mathrm{~b}$, subject $\mathrm{S} .01$ was still unable to understand the problem being asked in the question so that it was wrong to answer the relationship between the line and the point being asked in the question. In question number $3 \mathrm{~b}$, subject S.01 only writes the name of the line and marks it, not the relationship between the line and the point being asked in the question.

Based on the quotation from the interview dialogue, it shows that the subject S.01 can actually understand the problem in question number 3 and is able to describe the parts or angular points of the space well, but in question number 3 part b, the subject S.01 is not accurate understand what is asked in the question part $\mathrm{b}$, so that students are still wrong in completing or giving answers. This indicates that the S.01 subject has good spatial abilities in the aspect of mind rotation and includes the visualization thinking level (Level 0), which is able to solve problem number 3 part a correctly, but in part b, subject S. 01 still has difficulty due to not being thorough in understanding what is actually being asked or asked in the questions.

\section{Conclusion}

1. The level of students' spatial ability based on Van Hiele's level in the application of problem-based learning, all of 35 students have been able to reach Level 0 (visualization) in the aspects of spatial visualization and mental rotation; The number of students who reached Level 1 (analysis) was 24 students in the aspect of spatial perception and as many as 26 students in spatial orientation; There were 26 students who reached Level 2 (informal deduction) in the spatial relation aspect and 17 students in the spatial visualization aspect, 15 students who reached Level 3 (deduction) in the spatial perception aspect and as many as 16 students on the mental rotation aspect. Meanwhile, no one has managed to reach Level 4 (rigor).

2. The level of error or difficulty of students in solving problems based on Van Hiele's level, including:

a. Subject S.01 (low spatial ability), at Level 1 experienced skill difficulties (question number 1) and concept difficulty (question number 4), at Level 2 experienced skill difficulties, at Level 3 and Level 4 experienced difficulty in principle.

b. Subject S.02 (low spatial ability), has difficulty skills at Level 2 and has difficulty in principle at Level 3 and Level 4.

c. The subject of S.03 (moderate spatial ability) has difficulty in principle at Level 3 and Level 4. 
d. Subject S.04 (moderate spatial ability), has difficulty skills at Level 3 and has difficulty principles at Level 4.

e. Subject S.05 (high spatial ability), has difficulty in principle at Level 4.

f. Subject S.06 (high spatial ability), has difficulty in principle at Level 4.

\section{References}

Abdussakir and Nur Laili Achadiyah. 2009. Circular and Circle Area Learning with React Strategy for Class VIII Students of Mojokerto City Junior High School. Proceedings in the National Seminar on Mathematics and Mathematics Education FMIPA UNY, ISBN: 978-979-16352-3-2, pp 388-401

Amir, Z., and Risnawati. 2016. Psychology of Learning Mathematics. Yogyakarta: Aswaja Pressindo

Barke, HD and Engida, T. (2001) Structural Chemestry and Spatial Ability in Different Cultures. Chemistry Education: Research an Practice in Europe Vol 2. No. 3 pp.227239

Depdikbuk. 2012. Curriculum model for education unit level and syllabus development model for SMP / MTs subjects. Jakarta: BP Cipta Jaya

Fiantika F, R. 2017. Representation Elements of Spatial Thinking. Journal of Physics: Conference Series 824 (1), 012056

Irhamna, Amry, Z., and Syahputra, H. (2020). Contribution of Mathematical Anxiety, Learning Motivation and Self-Confidence to Student's Mathematical Problem Solving. Budapest International Research and Critics in Linguistics and Education (BirLE) Journal Vol 3 (4): 1759-1772.

Kartono. 2010. Hands on Activity in School Geometry Learning as Student Performance Assessment Vol 1, Mathematics Department, UNNES.

Nasution, Y.S., Syahputra, E., and Mulyono. (2020). The Development of Learning Instrument Using Problem Based Learning Model to Improve Critical Thinking of Junior High School Students. udapest International Research and Critics in Linguistics and Education (BirLE) Journal Volume 3 (3): 1501-1508.

National Academy of Science. 2006. Learning to Think Spatially. Washington DC: The National Academics Press.

Republika On Line. March, 2008. Seeing From the Eyes of World Watchers, html, 1.

Rezeki, R., Sitompul, H., and Situmorang, J. (2020). The Effect of Learning Strategies and Cognitive Styles on Learning Outcomes of Mathematics after Controlling Intelligence. Budapest International Research and Critics in Linguistics and Education (BirLE) Journal Vol 3 (2): 1151-1163.

Slameto (2010). Learning and the Factors that Affect It, Jakarta: Rineka Cipta.

Syahrir, S., Kusnadin, K., \& Nurhayati, N. 2013. Analysis of the difficulty of understanding the concepts and principles of the three-dimensional subject matter of class XI students of SMK Nursing Yahya Bima Prisma Sain: Journal of Mathematics and Natural Sciences Assessment and Learning, IKIP Mataram, 1 ( 1), 89-103. 